American Journal of Microbiology and Immunology
(ISSN: 2474-2910)

\title{
Prevalence and Associations of Hepatitis B Virus Infection among Students of Traditional Schools, East Nile Locality, Khartoum, Sudan
}

Amin A. Mohamed Musa ${ }^{1}$, Sondos A. Abd Alrahem², Shymaa A. Saeed ${ }^{2}$, Altayeb Abdulmonem $^{4}$, Khalid A. Mohamed ${ }^{3}$, Mamoun M A Homeida ${ }^{1}$

${ }^{1}$ Paediatrics, University of Medical Sciences and Technology, Sudan; ${ }^{2}$ Medical Laboratory Sciences, Department of Microbiology, University of Medical Sciences and Technology, Sudan; ${ }^{3}$ Sidra Medicine and Weil Cornel Medicine QA; ${ }^{4}$ Department of Surgery, Ibn Sina Hospital Ministry of Health, Khartoum, Sudan

\section{ABSTRACT}

Background: Hepatitis B virus (HBV) infection is a major health problem causing considerable morbidity and mortality from both acute infection and chronic sequels including chronic hepatitis, cirrhosis and hepatocellular cancer. Aim: To estimate the prevalence of hepatitis B virus infection and the associated factors among children and adolescent in the traditional schools, East Nile locality. Methods: Descriptive cross-sectional schoolbased study. Sero-prevalence survey was conducted among school children and adolescent aged 2-19 years. Total sample of 880 students were tested for Hepatitis B surface antigen (HBsAg) in serum using immune-chromatographic assay. Data were analyzed using IBM statistical package for social sciences version 20 with statistical significance of $(p<0.05)$. Results: A total of $4.2 \%$ tested positive for HBsAg, (3.2\%) among children and $(4.3 \%)$ among adolescent, this is lower than the reported prevalence in the country. There was no significant association between the pre-determined risk factors and hepatitis $B$ virus infection in the study group. Conclusion: The prevalence of HBV infections in this study was lower than the overall prevalence in Sudan. Further studies are needed to evaluate the risk factors for hepatitis B virus infection among children and adolescents in Sudan. Hepatitis B virus vaccine should be implemented in the vaccination program for children, in addition to awareness campaigns about the virus and transmission methods.

Keywords: Hepatitis B Virus, Children, Adolescent, Traditional Schools.

*Correspondence to Author:

Khalid A Mohamed

Senior Attending Physician, Sidra Medicine , Doha, Qatar, Po Box 26999

How to cite this article:

Amin A. Mohamed Musa, Sondos A. Abd Alrahem, Shymaa A. Saeed, Altayeb Abdulmonem, Khalid A. Mohamed, Mamoun M A Homeida. Prevalence and Associations of Hepatitis B Virus Infection among Students of Traditional Schools, East Nile Locality, Khartoum, Sudan. American Journal of Microbiology and Immunology, 2021, 6:10.

\section{eScîPub}

eSciPub LLC, Houston, TX USA. Website: http://escipub.com/ 


\section{Introduction}

Hepatitis B virus (HBV) infection is a major health problem causing considerable morbidity and mortality from both acute infection and chronic sequels including: chronic hepatitis, cirrhosis and hepatocellular cancer. Two billion people show evidence of past or current HBV and over 350 million people are chronic carriers worldwide. Three quarters of the world's population live in areas with high levels of infection (Mudawi et al., 2008). Sub-Saharan Africa has the second largest global burden of chronic carriers of hepatitis B infection after Asia (Christopher et al., 2015). Sudan is an African country with high HBV prevalence of greater than $8 \% \mathrm{HBsAg}$-positivity, ranging from $6.8 \%$ in central Sudan to $26 \%$ in southern Sudan. HBV infection occurs in early childhood in southern Sudan, with the infection increasing with age in northern Sudan (Mukhlid et al., 2013).

Annually, there are almost 2 million new infections in children younger than 5 years worldwide, mostly through mother-to-child transmission, and early horizontal transmission (Giuseppe et al., 2019).There are several modes of transmission of HBV infection including: exposure to infectious blood or body fluids. In areas where the infection is common the most frequent method by which hepatitis $B$ is acquired is vertical transmission at the time of birth or from close contact with other people during childhood, while in other areas where the infection is uncommon, intravenous drug use and sexual intercourse are the most frequent routes of infection. In addition to that, there are other risk factors including working in healthcare, blood transfusions, and dialysis (Babbiker et al., 2018). This study aim to estimate the prevalence of hepatitis B virus infection and the associated factors among children and adolescent of traditional schools, in the East Nile locality of the state of Khartoum, Sudan.

\section{MATERIALS AND METHODS}

Study design:
This was a descriptive cross-sectional schoolbase study.

\section{Study area:}

The study was carried out in traditional schools of Eid-Babiker village, nearly 20 kilometers east Khartoum. These are male-only institutions.

\section{Sampling and Sample size:}

All male children and adolescents attending the traditional schools of Eid-Babiker village were included, 880 samples were collected. Consent was obtained for participation in the study and for the blood withdrawal.

\section{Data collection}

\section{Socio-demographic data collection}

Interview based questionnaire was filled for all participants contain socio-demographic and clinical information such as age, origin of birth and family history, in addition to risk factors for hepatitis B infection were obtain.

\section{Sample collection and processing:}

A volume of $3-5 \mathrm{ml}$ blood was collected from each patient through venipuncture technique then displaced into a plain container. Each blood sample was centrifuged at $3000 \mathrm{~g}$ for $5 \mathrm{~min}$ to serum (Purusotam et al., 2017).

Serum sample were tested for $\mathrm{HBsAg}$ at the sites with Humasis HBsAg Card, Humasis Co., Ltd, Republic of Korea. (Relative Sensitivity: 98\% (97/98), Relative Specificity: >99\% (98/98), Accuracy 99\% (195/196)). Humasis HBsAg card is one step in vitro diagnostic test base on an immune-chromatographic assay. It is designed for qualitative determination of Hepatitis B surface antigen (HBsAg) in human serum or plasma specimen.

\section{Data analysis}

Data was analyzed by IBM Statistical Package for Social Sciences (SPSS) version 20 in terms of frequency table to estimate prevalence and binary logistic regression test was done to determine the association between the risk factor and hepatitis B infection. A value of 0.05 was used as alpha level of significance.

\section{Results:}

AJMI: http://escipub.com/american-journal-of-microbiology-and-immunology/ 
Over a period of one month, 880 students were selected for the study. The age range was $2-19$ years with a mean $12.42 \pm 2.458$ years. Out of 880 individual, $62(7 \%)$ were children under the age of 12 while the rest $818(93 \%)$ were adolescents. Showed in Table 1. Of the study population 37 (4.2\%) tested positive for HBsAg, of them 2 were children while 35 were adolescents This gives a prevalence figure of $(3.2 \%)$ in children and $(4.3 \%)$ in adolescents. The results are shown in Table 2.

Identified risk factors for HBV infection among individual were a personal history of jaundice $(21.9 \%)$ family history of jaundice $(25.3 \%)$ and a history of jaundice in a parent (12\%). Numerous tools were shared on a large scale including; Cups (57.6\%), Nail clippers (40.3\%) and Beds (25\%). Minority of individual shared Combs $(15.7 \%)$, Razors (16\%) and tooth brushes (6.1\%).

Other risk factors included traditions such as whipping in social events (68.2\%) and participating in mass circumcision (24.5\%). In addition to traditional medical practice including; cupping (31.8\%) and moxibustion (30.2\%).
No association found between the identified risk factors and hepatitis $B$ virus infection among the study participants $(P>0.05)$. Showed in Table 3 .

\section{Discussion:}

Viral hepatitis poses an important burden on children's health worldwide. Resaerch has shown that hepatitis B virus infection is an important cause of chronic liver disease in children and adolescents (Griselda et al., 2012). Sudan is an African country with high $\mathrm{HBsAg}$ prevalence greater than $8 \%$, ranging from $6.8 \%$ in central Sudan to $26 \%$ in southern Sudan (Mukhlid et al., 2013). However, there is very limited data regarding the prevalence of hepatitis $B$ virus infection among children and adolescent in Sudan.

Our study revealed a low prevalence of hepatitis $B$ virus in comparison to the reported prevalence in Sudan. It is likely that the study population has not been exposed to significant HBV infections risk factors. The prevalence was higher in adolescents but this may be a reflection of their higher representation in the study group compared to younger children.

Table 1: Shows the frequency and percent among the age group.

\begin{tabular}{|l|l|l|}
\hline Age Group & Frequency & Percent \\
\hline Children & 62 & 7 \\
\hline adolescent & 818 & 93 \\
\hline Total & 880 & 100 \\
\hline
\end{tabular}

Table 2: Shows the prevalence of Hepatitis B virus infection among study population and the two age groups.

\begin{tabular}{|l|l|l|l|}
\hline HBV infection & Overall & Children & Adolescent \\
\hline Positive & 4.2 & 3.2 & 4.3 \\
\hline Total & 100 & 100 & 100 \\
\hline
\end{tabular}


Table 3: Show the frequency and percent of risk factors and association with Hepatitis B virus infection.

\begin{tabular}{|l|l|l|l|}
\hline Risk factors & Frequency & Percent & P value \\
\hline History of jaundice & 193 & 21.9 & 0.361 \\
\hline Family history of jaundice & 223 & 25.3 & 0.291 \\
\hline Parents with jaundice & 106 & 12 & 0.508 \\
\hline Sharing Cups & 507 & 57.6 & 0.826 \\
\hline Sharing Nail clippers & 355 & 40.3 & 0.606 \\
\hline Sharing Beds & 220 & 25 & 0.204 \\
\hline Sharing Combs & 138 & 15.7 & 0.913 \\
\hline Sharing Razor & 141 & 16 & 0.181 \\
\hline Sharing Tooth brush & 54 & 6.1 & 0.765 \\
\hline Whipping in social events & 600 & 30.2 & 0.13 \\
\hline Mass circumcision & 216 & 659.2 & 0.13 \\
\hline Moxibustion & 280 & 355 \\
\hline Cupping & 64.8 & 0.13 \\
\hline
\end{tabular}

In addition our research did not find a significant relationship between the known risk factors and HBV virus in this group, this may be related to the low prevalence of the virus which in turns reduces the risk of horizontal transmission among the group. Two studies conducted in Sudan revealed higher prevalence of HBsAg. The first study estimated prevalence of hepatitis $B$ virus infection in the Gezira State of Central Sudan, children and adolescent had (12.5\%) and (6.5) HBsAg positivity respectively (Mudawi et al., 2008). The second study evaluated hepatitis B virus sero-prevalence among children with cancer, (21.3\%) were HBsAg positive (Mohammed et al., 2016). The first study included only 99 participants which may be too small to reflect on the whole population prevalence. In the second study, children with cancer are highly susceptible to HBV infection due to multiple predisposing factors such as blood transfusion.

In Nigeria adolescent had a relatively low prevalence of $\mathrm{HBsAg}(3.1 \%)$ in compare to this study (4.2\%). However, (6.5\%) adolescent males were positive for HBsAg which is higher than the findings form this study (4.3\%). Christopher et al included 420 students in his study, $50 \%$ were males.

Lower prevalence of $\mathrm{HBsAg}$ observed among children and adolescent from Rio de Janeiro 
(1.8\%) (LiviaMelo et al., 2014) Senegal (1.1\%) (Gora et al., 2019), and South Africa (0.4\%) (Prabdial-Sing et al., 2019) when compared to this study. All three countries have a have a national childhood Immunization program that includes HBV immunization.

The frequencies of HBV infections were observed in children (3.2\%), this pattern of results is consistent with previous studies conducted in Mexico (Griselda et al., 2012) and Indonesia (Takako U et al., 2010), where HBsAg prevalence was $(3.1 \%)$ in the two studies. This similarity may attributed to the fact that those countries has low intermediate to high intermediate HBV endemicity levels among the children and adolescents and no national immunization against HBV (J.J. Ott et al., 2012).

Mudawi et al reported no significant association between having history of jaundice and HBV infection (Mudawi et al., 2008). Sharing of tooth brush, razor and having history of jaundice were also not significant according to Christopher et al (Christopher et al., 2015). We report similar findings with none of the reported risk factors showing statistical significance for the infection.

\section{Conclusions:}

In conclusion, relatively low prevalence of HBV infections was observed in children and adolescents of Traditional Schools in East Nile Locality, Sudan. Moreover, none of the reported risk factors were associated with HBV infection. Further research in the community, including females, is needed to ascertain the community prevalence. National immunization against HBV should be funded to reduce the overall risk of this serious health problem.

\section{References}

[1]. Mudawi H.. Epidemiology of viral hepatitis in Sudan. Clinical and experimental gastroenterology, 2008; 1: 9-13.

[2]. Christopher B, Sylvester O, Oluchi M, Roland C, Isaac N, Anthony N, Bede C. Seroprevalence and Risk Factors of Hepatitis B Virus Infection among Adolescents in Enugu, Nigeria. Journal of Tropical Pediatrics, 2015; 61: 407-413.

[3]. Mukhlid Y, Hatim M, Sahar B, Dieter G, Anna K.. Molecular characterization of hepatitis $B$ virus in liver disease patients and asymptomatic carriers of the virus in Sudan. BMC Infectious Diseases, 2013; 13:328.

[4]. Giuseppe I, Philippa E, Geoffrey D, George S, Mei-Hwei C, Claire T, Marc B, et al.. Hepatitis B virus infection in children and adolescents In: Viral hepatitis in children and adolescents Series. Lancet Gastroenterology Hepatology 2019; 4: 466-76.

[5]. Babbiker M, Humodi A.. Frequency of HBV among Hepatocellular Carcinoma Patients in Khartoum State, Sudan. Journal of Carcinogenesis and Mutagenesis, 2018; 9 (3):14.

[6]. Purusotam R, Madhu D, Megha R, Huang L, Subash D.. Prevalence and risk factors of hepatitis B infection among mothers and children with hepatitis $B$ infected mother in upper Dolpa, Nepal. BMC Infectious Diseases 2017; 17:667.

[7]. Griselda E, Nora A, Sonia R, Monserrat M, Eloy Z, Arturo P.. Prevalence of hepatitis A, B and C serological markers in children from western Mexico. ANNALS of Hepatology, 2012; 11(2):194-201

[8]. Mohammed A, Tarig H. Hepatitis B Virus Seroprevalence among Children With Cancer in Sudan.. Pediatric Blood Cancer. 2016; 63:124126.

[9]. LiviaMelo V, Luciane A, Adilson J, Vanessa S, Lia L, Elisabeth L.. Low Prevalence of Hepatitis $B$ and $C$ Virus Markers among Children and Adolescents. BioMed Research International. 2014: 1-5.

[10]. Gora L, Amina S, Halimatou D, Ndiaye B, Niokhar N, Sokhna M, Babacar N, et al.. Pan African Medical Journal. 2019; 1937:1-9.

[11]. Prabdial-Sing N, Makhathini L, Smit S, Manamela M, Motaze NV, Cohen C, et al.. Hepatitis B sero-prevalence in children under 15 years of age in South Africa using residual samples from community-based febrile rash surveillance. PLoS ONE. 2019; 14(5): e0217415.

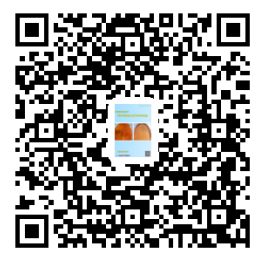

AJMI: http://escipub.com/american-journal-of-microbiology-and-immunology/ 